\title{
The impact of biotechnology and pharmaceutical industries on regional economies during the epidemic period
}

\author{
Yinuo Li
}

Jinan foreign language school, Jinan, Shandong, China, 250000

*Corresponding author. Email: cshier330@gmail.com

\begin{abstract}
The COVID-19 pandemic has had a huge impact on the global economy. Most of the region's "non-essential" businesses were ordered to shut down by the government. Also, only necessary productive activities were allowed to operate, so most of the region's GDP was kept below. In that case, biotechnology and pharmaceutical industries as the important roles of anti-epidemic businesses are affirmatively allowed to take place. Most people believe that biotechnology and pharmaceutical industries are able to alleviate the negative economic impact of the region where the industries are located caused by the epidemic. In this thesis, two regions with similar GDP [1] before the epidemic but different industrial structures were used to find out if the idea above is true. This article explains the reasons for choosing these two cities and the author will compare their economic conditions during and after the epidemic. One is San Diego, a city that has studied biotechnology and pharmaceutical industries, and the other is Phoenix, which lacks biotechnology and pharmaceutical industries. Although the business activities of the biotechnology and pharmaceutical industries were essential activities during the epidemic period and were not suspended, the author found that they did not greatly promote the regional economy during the epidemic period. But the biotechnology and pharmaceutical industries did play important role in the fight against the pandemic. Therefore, it is still important for the government to develop biotechnology and pharmaceutical industries to recover the economy as soon as possible after the epidemic.
\end{abstract}

Keywords: Regional economy, Biotechnology and pharmaceutical industries, GDP, epidemic

\section{INTRODUCTION}

Biotechnology and pharmaceutical industries are part of emerging industry clusters that are young, fastgrowing industries. These emerging industry clusters represented by biotechnology and pharmaceutical industries are making more and more contributions to the growth of the regional economy. A number of studies have found the positive and negative impacts of emerging industries on regional economies. The positive impacts shown in some studies include enriching economic diversity, increasing economic vitality, and developing the regional economy. Other studies [2] point out the negative impacts of emerging industries, such as rising unemployment among low-skilled, causing traffic congestion, and so on. However, there are few studies on the impact of emerging industries represented by biotechnology and pharmaceutical industries on the regional economy, and there is a lack of clear evidence that emerging industries represented by biotechnology and pharmaceutical industries could help the economy recover from relative stagnation during the epidemic period. In this thesis, the author compares two different regions, San Diego, California, which with emerging industries, especially biotechnology and pharmaceutical industries, and Phoenix, Arizona, which had a GDP about San Diego before the epidemic period [1]. The comparison is made to figure out whether biotechnology and pharmaceutical industries are able to alleviate the negative economic impact of the region where the industries are located caused by the epidemic. To be more specific, the author explores the influence of biotechnology and pharmaceutical industries on the regional economy by comparing the economic recession of the two regions during the epidemic. In that case, this thesis is able to illustrate that whether biotechnology and pharmaceutical industries can significantly play positive roles in the recovery of the regional economy during the epidemic period. 


\section{OVERVIEW OF THE EPIDEMIC SITUATION}

People have been suffering from COVID-19 since late 2019. Because of the contagious virus, countries had to take measures to intercept the spread of the epidemic. Most countries eliminated non-essential business and kept only essential activities, such as health services, medical innovation, to prevent the spread of the disease. Under such conditions, the global economy has become depressed since the outbreak. In San Diego County, where San Diego is, about 155,600 people were diagnosed and about 1500 people died from COVID-19 in 2020 [3]. In Maricopa County, which includes Phoenix, the epidemic was more serious than in San Diego. In 2020, about 520,200 people were diagnosed and about 8900 people died from COVID-19 [3]. San Diego County's CDC Social Vulnerability Index (SVI) is 0.5596 lower than 0.6354, which is Maricopa's CDC Social Vulnerability Index (SVI) [4]. The CDC's Social Vulnerability Index (SVI) summarizes how socially vulnerable a community is to disaster. The higher the SVI, the more vulnerable the community is to disaster. Namely, Maricopa County is more vulnerable to the epidemic than San Diego County. Also,San Diego's vaccination rate and population are significantly higher than Phoenix. There were $20,705,050$ people in California who have been vaccinated, and the vaccination rate is $52.70 \%$. Arizona is lower than California, with only 3,280,377 people vaccinated and a vaccination rate of $46.52 \%$ [4]. Overall, California, where San Diego is located, is faring better than Arizona, where Phoenix is located in the response to COVID-19.

\section{REGIONAL ECONOMIC ANALYSIS}

\subsection{Industrial structures}

San Diego, which ranks as the third-largest U.S. biotechnology cluster, is home to more than 400 biotechnology companies and institutions. Many international pharmaceutical enterprises have set up headquarters or branches here, such as Pfizer, Novartis,

Table 1 GDP of San Diego in regular years

$\begin{array}{ll}\text { year } & \begin{array}{c}\text { total gross domestic product of San } \\ \text { Diego [5] }\end{array} \\ 2001 & 117083.125 \\ 2002 & 124847.611 \\ 2003 & 134395.268 \\ 2004 & 145709.061 \\ 2005 & 157310.766 \\ 2006 & 164992.812 \\ 2007 & 171522.078 \\ 2008 & 171073.628\end{array}$

Amgen, Merck, and so on. In San Diego County, biotechnology and pharmaceutical industries have already become pillar industries. San Diego has a strong communications industry. Also, military bases play an important role in the economy of San Diego. The electronics and shipbuilding industries have developed rapidly and have taken on a considerable scale. Phoenix, the fifth-largest city in the United States, had an early economy dominated by agriculture. Over the last 40 years, the economy has diversified as the population has grown rapidly. As the capital of Arizona, many of its residents are government employees. Many high-tech and communications companies have moved to Phoenix in recent years. With mild winters, Phoenix benefits from seasonal tourism and sightseeing. The U.S. military also has an airbase in Phoenix, and Phoenix also has part of the mining industry. The industrial structure of San Diego and Phoenix seem similar, but there are significantly fewer biotechnology and pharmaceutical industries in Phoenix than in San Diego.

\subsection{Regular regional economies without the epidemic}

The economic situation of San Diego and Phoenix was similar for many years before the epidemic. In 2019, the total gross domestic product of San Diego is $253,117.792$ million dollars a little bit lower than the total gross domestic product of Phoenix, which is 272,113.776 million dollars [5]. Moreover, the two regions have similar GDP growth. In addition to the negative GDP growth in 2007 and 2008 due to the subprime mortgage crisis, the economies of the two regions had been growing steadily from 2000 until 2019. San Diego's average annual GDP growth rate from 2000 to 2019 was $4.41 \%$, and Phoenix's average annual GDP growth rate from 2000 to 2019 was $4.54 \%$. Figures 1 and 2 respectively show the economic information of San Diego and Phoenix from 2001 to 2019. The annual GDP growth rate is two decimal.

Units: Millions of Dollars, Not Seasonally Adjusted annual GDP growth of San Diego annual GDP growth rate of San Diego

$\begin{array}{rr}7764.486 & 6.63 \% \\ 9547.657 & 7.65 \% \\ 11313.793 & 8.42 \% \\ 11601.705 & 7.96 \% \\ 7682.046 & 4.88 \% \\ 6529.266 & 3.96 \% \\ -448.45 & -0.26 \%\end{array}$




$\begin{array}{lrrr}2009 & 166040.899 & -5032.729 & -2.94 \% \\ 2010 & 168687.239 & 2646.34 & 1.59 \% \\ 2011 & 174636.986 & 5949.747 & 3.53 \% \\ 2012 & 180309.903 & 5672.917 & 3.25 \% \\ 2013 & 191006.452 & 10696.549 & 5.93 \% \\ 2014 & 201384.751 & 10378.299 & 5.43 \% \\ 2015 & 213594.695 & 12209.944 & 6.06 \% \\ 2016 & 220259.799 & 6665.104 & 3.12 \% \\ 2017 & 230605.088 & 10345.289 & 4.70 \% \\ 2018 & 242242.089 & 11637.001 & 5.05 \% \\ 2019 & 253117.192 & 10875.103 & 4.49 \%\end{array}$

Units: Millions of Dollars, Not Seasonally Adjusted

Table 2 GDP of Phoenix in regular years

$\begin{array}{cr}\text { year } & \text { total gross domestic product of } \\ 2001 & \text { Phoenix [5] } \\ 2002 & 123966.933 \\ 2003 & 129964.926 \\ 2004 & 139687.463 \\ 2005 & 149681.693 \\ 2006 & 166921.151 \\ 2007 & 180986.929 \\ 2008 & 189702.566 \\ 2009 & 186051.12 \\ 2010 & 173214.943 \\ 2011 & 175091.722 \\ 2012 & 182632.386 \\ 2013 & 192596.109 \\ 2014 & 197918.359 \\ 2015 & 206225.091 \\ 2016 & 218258.928 \\ 2017 & 229281.49 \\ 2018 & 240890.139 \\ 2019 & 257292.963 \\ \end{array}$

annual GDP growth of Phoenix

5997.993
9722.537
9994.23
17239.458
14065.778
8715.637
-3651.446
-12836.177
1876.779
7540.664
9963.723
5322.25
8306.732
12033.837
11022.562
11608.649
16402.824
14820.813

annual GDP growth rate of Phoenix

\subsection{Economic forecasts for regular years}

Based on the GDP of San Diego and Phoenix after 2009 since they do not take into account the impact of the subprime crisis, people are able to use formulas to extrapolate the GDP of these two regions in 2020, if there was no pandemic in a regular year. Setting the independent variable 2009 as $x=1$, followed year by $x=2$, $x=3, x=4$, and so on. Meanwhile, the annual GDP of the region is set as the dependent variable y. Figure 1, which expresses the information of San Diego, gives us the formula $\mathrm{y}=336.86 \mathrm{x} 2+5048.5 \mathrm{x}+158021$. This

formula's coefficient of determination is 0.9959 , which means that the formula's predicted value is very close to the true value. In that case, using this formula, people are able to calculate that San Diego's GDP in a regular year in 2020 should be about 267110.84 million dollars. Similarly, figure 2, which expresses the information of Phoenix, gives us the formula $y=596.28 \times 2+2770 x+$ 169180. This formula also is reliable since the coefficient of determination is 0.9985 . Then, by substituting the independent variable $\mathrm{x}=12$, it is able to be calculated that the GDP of Phoenix in 2020 in a regular year should be about 288284.32 million dollars. 


\section{Unit: millions of dollars}

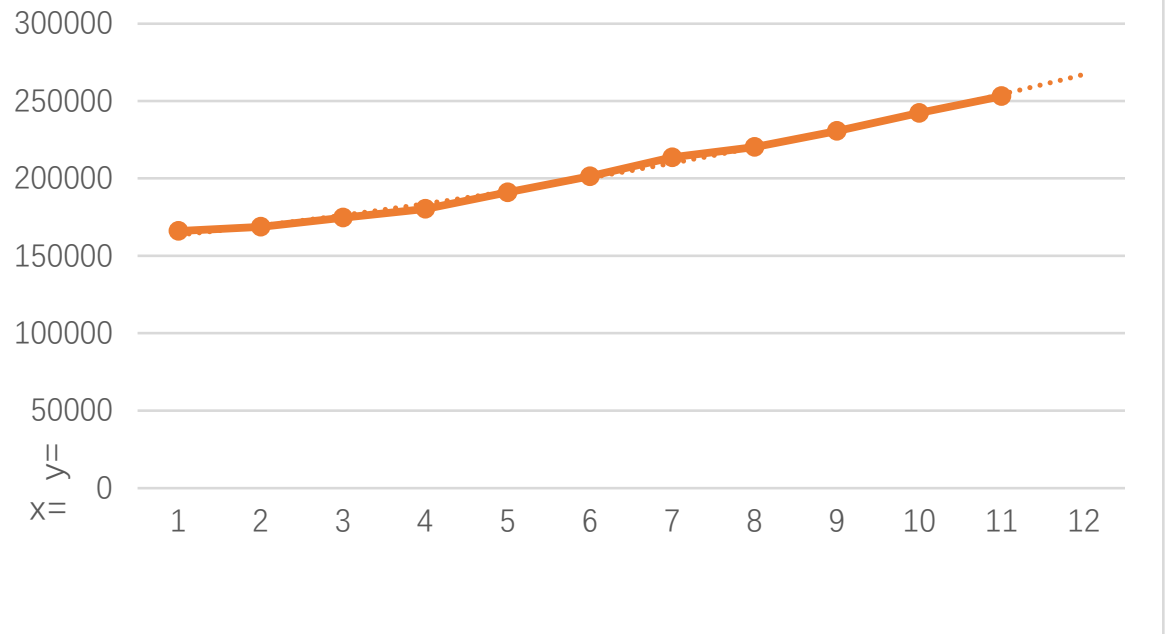

Figure 1. Economic forecasts for regular years in San Diego

\section{Unit: millions of dollars}

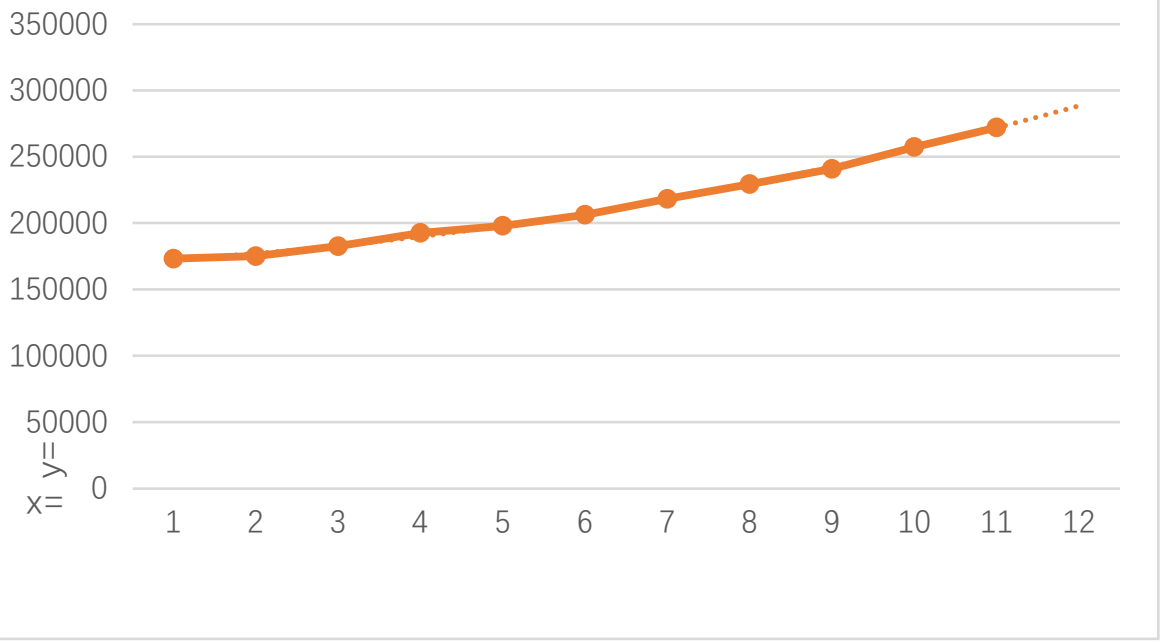

Figure 2. Economic forecasts for regular years in Phoenix

\subsection{Regional economies during the epidemic period}

However, due to the impact of the "shutdown" policy during the epidemic, the GDP of both regions is lower than predicted above. Since there is no exact estimate for metropolitan GDP in 2020, people can only predict it from published state GDP. The GDP of California totaled 12531202.3 million dollars in 2019 [5], of which San Diego accounted for 253117.192 million dollars or about $2 \%$ of California's GDP for years. Assuming that San Diego accounts for 2\% of California's GDP every year, then based on California's GDP of 12367486 million dollars in 2020 [6], San Diego's GDP in 2020 would be about 247349.72 million dollars. This is only about $92.60 \%$ of GDP predicted by the formula. Similarly, the GDP of Arizona totaled 1480476.4 million dollars in 2019 [5], of which Phoenix accounted for 272113.776 million dollars, or about $18 \%$ of Arizona's GDP for years. Assuming that Phoenix accounts for 18\% of Arizona's GDP every year, then based on Arizona's GDP of 1489843.8 million dollars in 2020 [6], Phoenix's GDP in 2020 would be about 268171.884 million dollars. This is only about $93.02 \%$ of GDP predicted by the formula. Since the regional economies are predicted in the same method, it can be obviously excluded that the errors in the forecast lead to the difference between the two economies. As a result, the GDP growth rate of the regional economy is only caused by the difference in the state economy, and San Diego's economy has indeed been negatively affected by the pandemic, just like Phoenix's. 


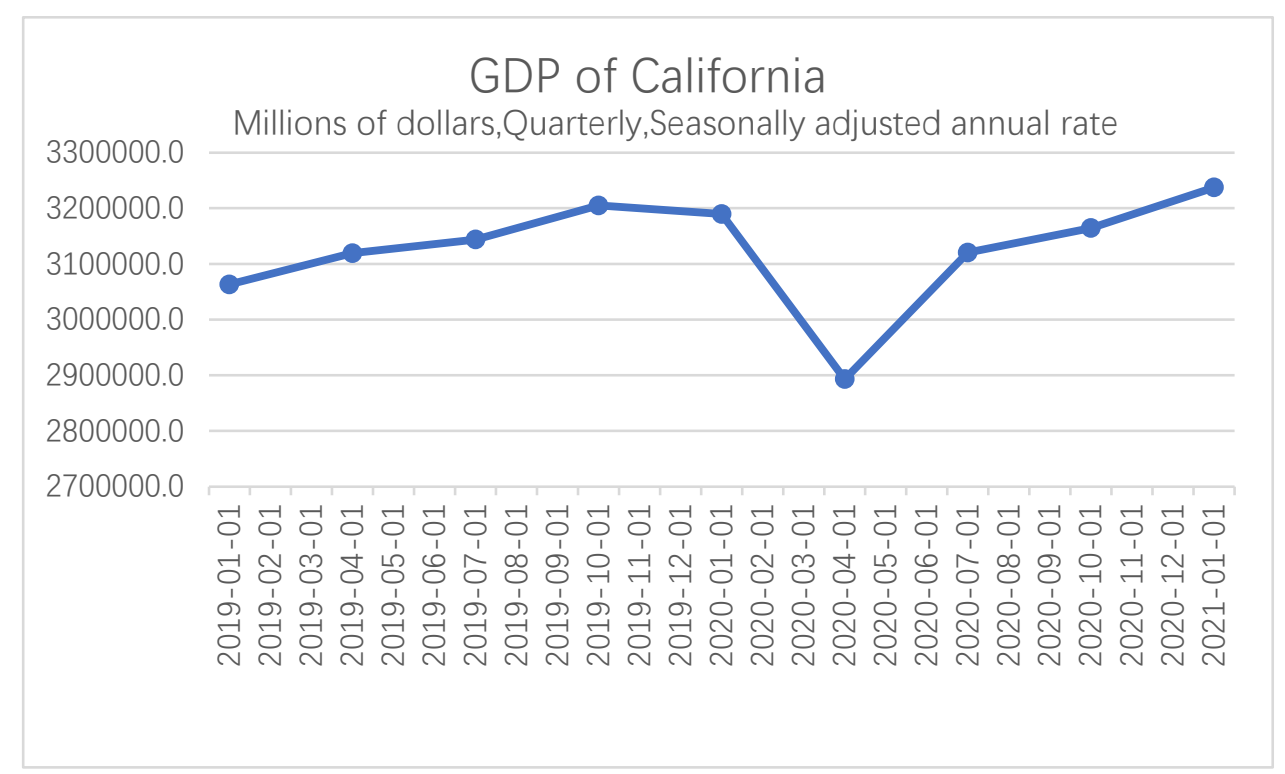

Figure 3. GDP of California during the epidemic

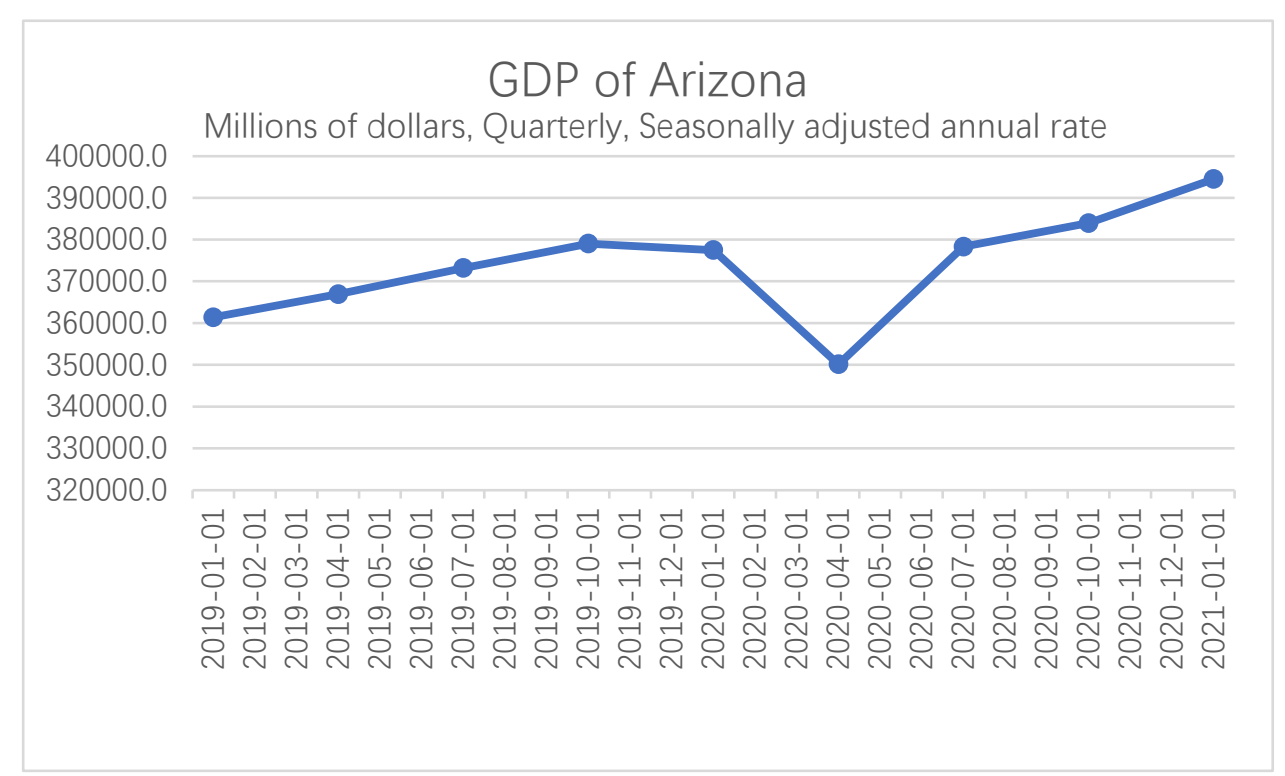

Figure 4.GDP of Arizona during the epidemic

\section{DISCUSSION}

To figure out whether biotechnology and pharmaceutical industries are able to promote the regional economy during the epidemic, the author compares San Diego and Phoenix. It is clear that San Diego has similar industrial structures to Phoenix, but has significantly more biotechnology and pharmaceutical industries. Thanks to better healthcare resources, San Diego has fewer COVID-19 infections, fewer deaths, and a higher vaccination rate than Phoenix, which indicates biotechnology and pharmaceutical industries are able to help the community to overcome the epidemic more easily. By comparing the GDP of the two regions in a normal year calculated by the formula with the actual GDP forecast based on the state economy, the result suggests that San Diego, which has biotechnology and pharmaceutical industries, has not diminished the negative economic impact of the epidemic. Due to the short duration of the epidemic, previous studies on emerging industries and regional economies have been sufficient, but there are still few related studies in the special period of the epidemic. Because of the current lack of metropolitan GDP in 2020, this thesis relies only on the GDP of individual states in 2020. In that case, it is possible that the predicted data is not accurate, but this is not an error due to a defect in the formula, nor does it affect the conclusion. This study reveals that government can bring the epidemic to an end as soon as possible by developing biotechnology and pharmaceutical industries to further reduce the negative economic impact of the epidemic. It is obvious that biotechnology and 
pharmaceutical industries have not been suspended in the outbreak, but still not the cause of promoting local economic recovery. The authors speculate the reason may be due to medical innovation is a long process, not immediately produce income and require upfront costs into, or biotechnology and pharmaceutical industries mainly employ knowledge-based talents, cannot create jobs like manufacturing widely. However, these reasons are the only speculation by the author, and more research is needed on the exact causes of these problems in the future. Also, more regional comparisons should be made to determine the impact of biotechnology and pharmaceutical industries on the economy during the epidemic period, since only comparing two regions may not be sufficient.

\section{CONCLUSION}

This thesis uses formulas to predicted the regional GDP in the regular year and compares it with the real regional GDP calculated by the GDP of the states in which the regions are located. Then, by comparing a region with biotechnology and pharmaceutical industries to another region with a similar economy before the epidemic, the result shows that the epidemic situation of San Diego was less serious than the epidemic situation of Phoenix, but the economy of San Diego with biotechnology and pharmaceutical industries did not have a better performance than the economy of Phoenix. This result means that biotechnology and pharmaceutical industries are able to help the community overcome the epidemic more easily instead of recovery from the negative economic impact of the outbreak. Also, it is different from the widely held belief that biotechnology and pharmaceutical industries are helping the economic recovery by continuing to operate. However, this thesis may still be somewhat one-sided, as it does not exclude the economic impact of other factors on the study regions. Overall, the results suggest that biotechnology and pharmaceutical industries, while not economically mitigating the negative impact of the pandemic, are more likely to help regional communities overcome the pandemic. In that case, this innovative study may have implications for government expenditure. Specifically, the government can support biotechnology and pharmaceutical industries to overcome the epidemic as soon as possible, but it cannot rely on biotechnology and pharmaceutical industries for economic recovery after the epidemic.

\section{ACKNOWLEDGMENT}

Throughout the writing of this thesis, I have received a great deal of support and assistance. I would first like to thank professor Martha Olney, UC Berkeley, whose expertise was invaluable in the initiation of me in economics. Your insightful feedback pushed me to sharpen my thinking and brought my knowledge to a higher level. I would also like to thank my parents for their wise counsel and sympathetic ear. You are always there for me. In addition, I could not have completed this thesis without the support of my sister, Chunying $\mathrm{Xu}$, who always loves me very much and provides stimulating discussions as well as happy distractions to rest my mind outside of my research. Finally, I would like to thank Helen $\mathrm{Xu}$, who let me face up to finishing this thesis seriously.

\section{REFERENCES}

[1] U.S. Bureau of Economic Analysis. (2018). GDP by County, Metro, and Other Areas

[2] Sable, M. (2007). The impact of the biotechnology industry on local economic development in the Boston and San Diego metropolitan areas. Technological Forecasting \& Social Change, 74, 3660.

[3] Johns Hopkins Coronavirus Resource Center. (2020)

[4] Centers for Disease Control and Prevention. (2021)

[5] U.S. Bureau of Economic Analysis. (2020). GDP by County, Metro, and Other Areas

[6] U.S. Bureau of Economic Analysis. (2021). GDP by County, Metro, and Other Areas 